\title{
TORSION FALLOPIAN TUBE
}

(A Case Report)

\author{
Lt Col AD DWIVEDI ${ }^{*}$, Lt Col JYY FALLEIRO, sM+, \\ Maj S DEBNATH ${ }^{\#}$
}

MJAFI 1997; 53: 315-316

KEYWORDS: Haematosalpinx; Torsion pelvic organs.

\section{Introduction}

$\mathbf{N}$ ormal fallopian tube or chronically inflamed fallopian tube is known to undergo torsion producing acute abdomen, clinically simulating a disturbed cctopic gestation. In the absence of diagnostic aids like ultrasonography (USG), laparoscopy and beta human chorionic gonadotrophin estimation, it is difficult to differentiate this condition from disturbed ectopic gestation. Torsion of tubc leads to haematosalpinx, haemoperitoneum and gangrene of tube necessitating laparolomy and salpingectomy. This condition is not common, Sir N Jeffcoate reported 6 cases [1] and Diamant $Y Z$ et al reported only 4 cases [2]. This importance of an early diagnosis of torsion of tube, by USG and laparoscopy, on which salvage of tube depends, is emphasised.

\section{Case Repert}

A 23-ycar-old female, casc ol primary infertility of 4 years durblion, was admitted with complaints of bleeding per vaginum of 3 days duration, severc colicky pain in lower abdomen and vomiting of 8 hours duration. There was history of anenorrlioca for 33 days without any syncopal attacks. Her menstrual cycles were regular.

On examination she had tachycardia (pulse $100 / \mathrm{min}$ ) with blood pressure $120 / 80 \mathrm{~mm}$ of $\mathrm{Hg}$. There was no pallor or pyncxia. There was no distension of abdomen, guarding and marked tenderness was present in left iliac fossa. Bowcl sounds were present. Pervaginal examination revealed bleeding with healthy and lirm cervix. However, due to marked tenderness in len fornix, size of uterus could not be made out. Movenent of cervix was very painful. The pouch of Douglas was also tender on palpation. A provisional diagnosis of tubal ubortion or acute salpingitis was made.

On investigation haemoglobin was II gim per cent, total leuencyte count $8800 / \mathrm{cu} \mathrm{mm}$ and nomal differential leucocyte count. Iler blood group was B Rh negative. Rindom blond sugar was $96 \mathrm{mg}$ per cent. Urinc routine examination was not contributory and Gravindex test was negrative.

She was placed on conservative management with intravenous fluids, injection Ampicilin $500 \mathrm{mg}$ intravenous 6 bourly and injection Gentamycin $60 \mathrm{mg}$ intravenous 8 hourly. Monitoring of pulse, respiration and blood pressure was continued. Pain abdomen increased over the following 6 hours and guarding became more prominent with increased tenderness in left fomix.

As the facility of USG or laparoscopy was not available, exploratory laparotony was carried out under general anaesthesia. There was about $100 \mathrm{~mL}$ of frec blood in the peritoneal cavity. Left fallopion tube was distended with blood and had turned gangrenous in its complete length due to torsion on mesosalpinx. Left ovary and ovarian ligaments were not involved. The utcrus, round ligaments and broad ligaments were nommal. Ovaries were healthy but right tube had evidence of chronic salpingitis and narrowing of fimbrial ostium without any adillesions or bands. However, possibility of ectopic gestation with torsion could not be ruled out. Salpingectomy on len side was done and tube was sent for histopathological examination. Post-operatively she made an uneventful recovery and was discharged on 7 th post-operative day.

Histopathological examination showed transmural ischacmic necrosis, with lumen of the tube filled with blond and proteinaceous exudate. The mucosal folds showed an acute on chronic inflammatory cell infiltrate. No gramulomas were found. Multiple scetions were sludied but no evidence of cetopic gestation was found. A diagnosis of ischaemic necrosis with hacmatosalpinx due to torsion and acute on chronic salpingitis was made.

\section{Discussion}

Torsion of a normal tube is known to occur in young and adolescent girls with symptoms of acute abdomen having history of similar attacks and remissions in the past [3]. However, in reproductive age group it is preceded by one or other pathology of tubes. Patients, with torsion of tube, present with pain lower abdomen, more on

"Classilicd Specialist (Obsıctrics \& Gynaccology), Mititary Hospital, Ambala Cantt, Haryana 13300I; 'Classificd Specialist (Pathology) I8I Military Hospital. C/o 99 APO; "Graded Specialist (Anaestliciology), 305 Ficld Ambulance, C/o 99 APO 
affected sidc, with vomiting and bowel irritability. The syncope, which oflen accompanics a disturbed ectopic gestation, may not be present. Clinically the differentiation from other causes of haemoperitoneum or acute inflammation of viscera like appendicitis or diverticulitis is not possible. Where facilities for further investigations are not available, recourse to laparotomy has to be made as salvage of tube depends on time passed since onset of symptoms. In such cases, an carly diagnosis and surgical intervention is of paramount importance.

Torsion of normal tube in childhood and adolescents is duc to unusual physiological mobility of organs. For similar mechanical reasons even small tumours with long pedicle can cause torsion of tube. In reproductive age group torsion of tubc can be preceded by salpingitis, hydrosalpinx, haematosalpinx, ectopic gestation, ovarian tumours and adhesions or bands. The torsion also could be initiated by asymmetrical growth of tumours, long mesosalpinx, tubal spasm, haemodynamic factors or sudden alteration of body position.

Irrespective of the initial cause or force which commences torsion of mesosalpinx or the pedicle, the further twisting is due to haemodynamics. Once torsion takes place, venous flow gets obstructed leading to congestion of tissues, ocdema and extravasation of blood forming haematosal- pinx and haemoperitoneum. Later, arterial blood supply gets affected and organ lurns gangrenous and nonviable.

Tubal torsion needs to be differentiated from acute salpingitis, ruptured cyst, ectopic gestation, acute appendicitis, acute diverticulitis, renal colic and other causes for intra-peritoneal haemorrhages. USG, laparoscopy and beta human chorionic gonadotrophin estimation can help in establishing an early diagnosis of such cases. The treatment reamains laparotomy followed by partial or total salpingectomy depending on extent of gangrene. In absence of other aids diagnostic laparotomy should be performed without delay to salvage the tube. Unfortunately this patient, a case of primary infertility, lost her left tube due to torsion and complete tube turning gangrenous and the right tube also was not healthy having evidence of chronic salpingitis with narrow fimbrial ostium.

\section{REFERENCES}

1. Sir Norman Jeffcoatc. Torsion of the pelvic organs. In: Principles of Gynaecology. London and Boston: Butterworth and Co Ltd, 1975; 280-2.

2. Diamant YZ, Aboulafia Y and Raz S. Torsion of Hydrosalpinx: Report of four cases. Int Surg 1972; 57: 303-4.

3. Provost MW. Torsion of the normal fallopian Tube. Obstet \& Gynaecol 1972; 39: 80-2. 